\title{
An Investigation into Benefits and Challenges of Total Quality Management: The Case of a Gauteng Municipality
}

\author{
Boitumelo Leenetse Mabele ${ }^{1, *}$, Shamila Singh ${ }^{2}$ \\ ${ }^{1,2}$ Academic, Management College of Southern Africa \\ *Corresponding Author: Boitumelo Leenetse Mabele, Academic, Management College of Southern \\ Africa, South Africa
}

\begin{abstract}
The purpose of the study was to investigate the extent to which Gauteng local government benefits from the implementation of Total Quality Management (TQM) and the challenges that prevents the municipality from achieving of full service TQM potential. The Gauteng region experiences poor service delivery and social delivery protests that plague Gauteng. The municipality regularly experience employee strikes and billing crisis. The implementation of TQM will eliminate these factors and enable the Gauteng municipalities to carry out its mandate as per the constitutional requirements.
\end{abstract}

Data was collected using semi-structured interviews. The data collected from the interviews was analysed using thematic analysis which is a qualitative data analysis technique. The target population for this study was 16 Organisational Development staff at the Gauteng municipality and the sample size was 14.

The results indicated that TQM had been poorly implemented to an extent that usage in Gauteng municipality was not visible. The other key finding was that top management did not support TQM implementation and this was a major contributing factor to the failure of the TQM programme. Furthermore, the study revealed that TQM had been poorly implemented hence its benefits had not been realised. In addition, the study revealed that the challenges that were encountered in TQM implementation included lack of leadership commitment, ineffective communication strategy, organisational culture which was not conducive for TQM implementation and politicians meddling in municipal business.

Keywords: Total Quality Management, Benefits, Challenges, Gauteng, Municipality

\section{INTRODUCTION}

The City of Johannesburg (2015:25) indicated in its Integrated Development Plan for 2015 and 2016 that the inhabitants of the City are currently estimated to be 4918 635. The impact of service delivery interruptions affects people economically and socially. It is also therefore imperative that services are optimised so that there is little to no negative impacts. The negative effects of industrial action by employees and poor service delivery that is constantly reported can be eliminated by the application of a TQM system. The elimination of these factors will enable the City of Johannesburg to carry out its mandate as per the constitutional requirements.

According to Mohanty and Lakhe (2011:1), TQM emphasises the incorporation and coordination of all functions in the course of a job and aims to achieve an unending improvement in quality. The quality being referred to include that of data, information, decisions, goals, plans, people, resources, equipment and systems. TQM finds its strongest roots in the enhancement of staff morale and the creation of an empowering work environment which in turn facilitates exceptional staff performance (Mohanty and Lakhe, 2011:1). TQM is important to any organisation in sustaining consistency in the context of continuous changes (Mohanty and Lakhe, 2011:1). TQM refers to the pursuit of brilliance, forming the correct behaviours and managing to prevent flaws and improve consumer satisfaction by heightened productivity and success (Mohanty and Lakhe, 2011:23). The service industry holds 23 per cent of the entire trade of the world and therefore it is imperative to improve this industry and the consequence is economic growth (Mohanty and Lakhe, 2011:23). The application of TQM in service industries is a huge task because of the characteristics of the service industries. Service firms must adopt TQM if they are to compete in the emerging global market (Mohanty and Lakhe, 2011:246). 
The study was aimed to broaden the understanding regarding the unique factors that present challenges in the implementation of TQM in the public sector. Many organisations have attempted to implement quality programmes in the last few decades especially private sector organisations.

The study was instigated by the perennial challenges regarding service delivery in the Gauteng. Gauteng municipalities regularly experiences employee strikes, billing crises and poor service delivery. These challenges are an impediment to the Gauteng achieving world class city status. The implementation of TQM might assist in addressing the issues of poor quality of service delivery. The study is also expected to reveal where Gauteng province municipalities had faltered in the implementation of TQM and make recommendations to address challenges regarding the quality management programme. The objectives of the study were as follows: the determination of the benefits of TQM implementation; the determination of the challenges of TQM implementation and making recommendations on how TQM could be implemented effectively in Gauteng municipalities. The study was conducted in the background of a service delivery system which has been experiencing numerous complaints and protests from Gauteng municipalities' clients who are unhappy with the inconsistent and poor service delivery.

\section{RESEARCH PROBLEM}

According to a report by Tandwa (2015:1), the Gauteng region experiences poor service delivery and many social delivery strikes. In addition, other issues plague the performance of City of Johannesburg, namely, employee strikes, the billing crisis, fewer non-renewable resources to name a few. In order to allevaite some of these challenges, the City of Johannesburg needs to develop a high performance system by adopting a TQM philosophy. Johannesburg intends to become a world class city that is constantly benchmarking itself against first world cities across the globe.

\subsection{Research Objectives}

The objectives of the study are as follows:

- To determine the benefits of TQM implementation;

- To determine the challenges of TQM implementation; and

- To provide recommendations on how to effectively implement TQM

\subsection{Research Questions}

From the above research objectives, the following research questions were derived:

- What are the benefits of TQM implementation?

- Which challenges are faced in TQM implementation?

- How can TQM be effectively implemented?

\section{LiTERATURE REVIEW}

Key definitions of quality and TQM that guide the study and are delineated herein below.

Quality does not only concern the features of physical products, but also those of processes such as in services. It is impossible to measure quality in an absolute sense but only relative to given requirements. TQM defines quality as conformance to correctly defined requirements that satisfy user needs (Mohanty and Lakhe, 2011:12). The ultimate goal of TQM is the provision of quality products and services that meet customer needs and expectation at a cost that represents the best value (Mohanty and Lakhe, 2011:12).

Brown (2014:299) states that eight aspects have been found in quality and these are: performance, characteristics, consistency, resilience, serviceability, aesthetics and professed. According to Schwalbe (2010:320), the cost of quality is defined as the cost incurred for not following procedures combined with the benefits derived from following procedure. Costs incurred for not following procedures refers to failure and not delivering the required quality by the consumer. The benefits derived from following procedures occur when an entity possess readily available services that are inline with the consumers' expectations. 
According to Simchi-Levi et al. (2009:368), organisations are now driven by consumer needs and the most important aspect is no longer the service provided instead it is the consumer's view of what value is. The method used to weigh service quality has changed from assessing quality internally to the outside consumer's gratification.

Chopra and Meindl (2016: 470) made an illustration of a purchaser who desires that the supplier enhances performance through the turnaround time for an item that is in season. This will enable the purchaser to have less stock on hand and meet the customer demand as well. The systems used by the organisations to control quality, are expected to assist with constant enhancements of process practices (PMBOK, 2013:227).

TQM focuses mostly on the enhancement of the confidence of employees and the establishment of an enabling environment for work that empowers employees to strive towards the achievement of exceptional human accomplishment. TQM concentrates on the above combination and the organisation of the different practices taking place within the business with the objective of constantly enhancing quality output. TQM can only thrive if an organisation's executive management is in support of quality improvements on all levels of the organisation and when an organisation's employees are empowered through skills development (Mohanty and Lakhe, 2011:13).

Kloppenborg and Timothy (2009:285) indicates that the fundamental principles of TQM are: departmental and individual education; esteeming employees, responsiveness, giving attention to potential, controlling creativity, paying attention to details, taking society concerns into account, goal orientated, value creation and systematic view of things. TQM incorporates the entire organisation from the lowest level to the highest level when creating processes that focus on the consumer, that are adjustable and embrace changes to the requirements. TQM is a well-known intervention and is highly esteemed in most industries in the 21st century. TQM requires that everyone within the organisation be bound by a desire for constant enhancement in achieving and surpassing consumer requirements (Brown, 2014:293).

\section{TQM IMPLEMENTATION TRENDS}

The important implementation of TQM in organisations has become an important concern for most stakeholders of both private and public organisations. It is essential to understand why there has been so much interest in TQM in the past few decades. Werner et al. (2011:399) described TQM as a culture within the organisation that is dedicated to the gratification of consumers though a combined system of tools, methods and exercises to constantly enhance services. TQM was also described as a philosophy that is meant to empower every member of the organisation (Gharakhani et al., 2013:47). The authors Werner et al. (2011:399) and Gharakhani et al.(2013:47) capture the high level objectives of TQM which are the gratification of consumers, continous enhancement or improvement and the empowerment of employees. Because TQM attempts to address all aspects of an organisation in its quest to achieve excellence, it has been labelled as a holistic and proactive approach to quality success in organisations (Nieuwenhuizen, 2011:227). As a consequence of this holistic and proactive approach, Altahayneh (2014:110) argued that the realisation of the success of TQM requires that all primary, supporting and managerial processess be designed in a manner that ensures quality for customers, employees and other stakeholders.

The implementation of TQM began in business organisations and then with the realisation of the its benefits, the quality movement extended to among other sectors education and government sectors (Suleman and Gul, 2015:123). Organisations that desire to achieve success adopt this quality philosophy in their organisations. According to Boulter et al. (2013:197), the operating incomes of organisations that adopt TQM tend to reflect improvement in financial performance. The implementation of TQM in the service industry only started gaining momentum in the past two decades, when service quality became important factor for success and business survival (Juneja et al., 2011:94). The implementation of TQM in the service industry has been met with challenges which include defining service quality (Juneja et al., 2011:94; Grubor et al., 2009:273). Al-Ibrahim (2014:124) highlighted that TQM as a quality framework had been used with variable success in the public sector, however there various arguments its use in the public sector. One of the views states that the public sector is a service driven sector and the TQM philosophy is well suited for it and the other view argues that the implementation of TQM in government is innappropriate as the goes of 
business and public sector are different (Al-Ibrahim, 2014:275). Chaston (2011:29) agreed with AlIbrahim (2014:275) on the first of the two views, but he added that TQM initiatives in public sector could be successful as long as the project leaders acknowledged that this was a more complex environment. According to Chaston (2011:29), in implementing TQM in the public sector it is essential to realise that top-down initiatives will fail and that just developing customer focus was not sufficient for the success of implementation.

\subsection{Quality Frameworks}

The views of the gurus on quality were consolidated into famous frameworks namely; Total Quality Management (TQM); International Organisations for Standardization (ISO) and Six Sigma (Kloppenberg and Timothy, 2009:284).

Total Quality Management According to Goetsch and Davis (2014:435), Total Quality Management has been explained to mean a path and not a certain place. It takes into account the broader facets involved in quality through combining quality control mechanisms to form a quality management system. TQM is based only on the system.

According to Schwalbe (2010:318), the International Organisations for Standardization (ISO) incorporates a system of nationwide standard organisations that function as partners with international institutes, authorities, businesses and organisations that represent customer.

Figfure 1: DMAIC methodology (Kloppenborg and Timothy, 2009:287)

\subsection{The Four Core Quality Concepts}

Kloppenborg and Timothy (2009: 285) stated the four key quality theories in an endeavour as: investor gratification, activity control, evidence-related control, enabled performance. PMBOK (2013:242) describes Quality Assurance to be the activity of examining the quality needs and the outcomes resulting from the assessment of quality management, this is done to confirm the suitable ideals and functioning. These practices are necessary to ensure that the activities lead to enhanced quality in all practices.

According to Brown (2014:298-299), the standards of TQM include a strong concentration on the consumer, developing the relationship with the consumers and contractors and an intense focus on constant enhancement. Under TQM all members of an organisation are viewed as consumers. Brown (2014:299) also stated that the standards of TQM also included enhancement in the overall quality within the organisation; precise analysis, numerical management also the shortened duration of rotation for recently introduced services and enabling the workers.

According to Brown (2014:289), TQM happens throughout the organisation, is built into the organisation's culture and reinforced by the leadership and quality is embraced at each and every level of the life of a service. TQM is again argued as the creation of control over the quality of the final service through the strategy of the business that is dedicated to enhancing consumer gratification (Brown, 2014:299).

Harrison et al. (2014) showed that TQM can be utilised and is also essential in the supply chain process where the example of Proctor and Gamble to bring together the entire chain of supply to achieve the output to the consumers, they functioned in reverse from the final output to ensure the desired service will be attained, at the desired location at the correct time and it must be of the aimed quality. The standards adopted by Proctor and Gamble are shortened as follows: develop every service that requires to be performed on a daily basis in the shortest time possible, constantly be in contact with suppliers, collect feedback for demand forecast and estimates directly from the customer, cooperate and have partnerships with all the providers involved in the chain of supply with a concentration on the customer satisfaction, it was emphasised that the collaboration happens inside and outside the organisation.

\subsection{Challenges in Implementing TQM}

The challenges which confronts implementation of TQM in public sector organisations emanated from the factor that government has poorly designed bureaucratic systems (Ready, 2007:14). Ahmad (2013:112) indicated that bureaucracy was an unavoidable part of modern governments which was 
enabled by democracy and the rule of law. This means the project leaders in TQM implementation in the public sectors are supposed to be cognissant of the challenges that are presented by government redtape. Politicians are present in local governments and their presence also complicates implementation of TQM. A study conducted by Cassia and Magno (2011:8) revealed that the division among public administrators and political officials being councillors contributed to the reasons why municipalities in Italy were struggling to implement quality improvement practices. The other factors that generally impact TQM implementation include leadership support. According to Calvo-Mora et al. (2013:115) the key results of the organisation relating to finances, innovation and technology can improve if leadership is focused towards a culture that is in support of quality. The success of TQM is greatly dependent on leadership and the commitment of senior management (Mosadeghrad, 2014:544). If leadership is not visibly showing its support for TQM initiative, the success of a TQM project hangs in the balance. Calvo-Mora et al. (2013:115) also brings up the issue of culture as an enabling factor in the smooth implementation of TQM. Nikolic and Nastasic (2010:60) argues that a strong organisational culture with innappropriate assumptions, values and beliefs posssess a strong negative impact on business succeess and makes it cumbersome to change strategy and the way things have been done. This also spells problems for TQM implementation. A study conducted by Jancicova and Brychta (2009:88) revealed that TQM and organisational culture were actually interrelated variables. The authors stated that if the system of quality management is successfully implemented it has an impact on organisational culture. On the other hand, an organisation's culture influences TQM implementation and its functionality. Khan (2006:6) suggested that a culture change was a prerequisite when dealing with matters of TQM implementation.

\subsection{Critical Success Factors for TQM}

The factors critical for the success of Total Quality Management implementation are discussed in the sections that follow.

\subsubsection{Leadership}

Leadership is identified by different scholars to be critical for the success of Total Quality Management implementation. Yu To and Lee (2012:420 - 438) found that leadership is critical in the process of improving quality, this outcome has been found to be consistent with Kanjis Business Excellence Measurement System, (2008:399415). The behaviour of leaders in the organisation can increase the likelihood that quality practices will be implemented smoothly through leadership and participation.

Calvo-Mora et al. (2013:115-143) found the critical success factors to be leadership style and constant enhancement. TQM demands tremendous commitment from senior management According to CalvoMora et al. (2013:115-143) the key results of the organisation relating to finances, innovation and technology can improve if leadership is focused towards a culture that is in support of quality. The success of TQM is greatly dependent on leadership and the commitment of senior management (Mohammad and Mosadeghrad, 2014:544-558).

\subsubsection{Human Capital Management}

Scholars agree that Human Capital is important to organisations planning to implement Total Quality management. Wickramasinghe (2012:836-850) identified that there is a need to involve Total Quality Management in the Human Resources activities. A positive relationship was identified with quality of the human capital management activities like training and education (TalibZillur and Qureshi, 2013:280318). The performance of the organisation in relation to finances, innovation and technology can improve if the manner in which human resources are managed is focused towards a culture that is in support of quality (Calvo-Mora et al., (2013:115143).

Psomas and Jaca (2016:380-398) found that factors that affect performance in an organisation were found to be related to human capital in the internal and external environment of the municipality. An analysis of the association between standards, qualities and TQM revealed that core virtues can contribute greatly when implementing Total Quality Management practices. These virtues bring about a spark that functions to enhance worker's motivation (Moccia, 2016:216-234). 


\section{Methodology}

The study followed a qualitative research methodology in which the researcher explored the central phenomenon of the benefits and challenges of TQM by posing broad general questions to participants and collects detailed views of participants usually in the form of words (Creswell and Clark, 2016:5). The research strategy used in this particular study was the interview strategy (Teddlie and Tashakkori, 2009:229).

The target population for the study consisted of 15 Organisational Development (OD) staff in the Gauteng's municipal offices. The research participants that were counted as being the target population were only those that had knowledge of TQM theory and implementation and worked fulltime within one the Gauteng municipalities OD department. The non-probability sampling technique used in this study was convenience sampling. Convenience sampling is a sampling technique which involves the selection of the units of the target population that are available and willing to provide the required information (Adams and Lawrence, 2015:129). The sample size was also 15 and the number of research participants who participated in the study was 14 . Houser (2015:192) argued that qualitative research does not use large numbers of participants and that the point of data saturation will determine the adequacy of the data.

The interview strategy was chosen because it provides research participants sufficient time to request clarification of questions and also affords interviewers the chance to obtain explanations of vague answers. According to Karami (2007:107), some of the advantages that the interview strategy gives to a researcher include correcting the research participant's misunderstandings and also keep track of the interviewee's attention. Data could also have been collected using a questionnaire. A questionnaire is described by Neelankavil (2011:160) as a series of questions on a specific topic, based on specific information needs or research goals that are posed to a respondent to provide answers.

Data analysis was conducted using thematic data analysis (Flick, 2014:26) as a data reduction and analysis technique which involves the segmentation, categorisation, summarisation and reconstruction of essential concepts discovered from the data sets. Qualitative research use the terms credibility; dependability; confirmability and transferability. Credibility and confirmability were achieved through rigorous data analysis and triangulation whilst dependability was achieved by keeping notes that guided the data collection process. In order to increase the transferability in the research, a detailed description of the research context was done and all assumptions central to the research were thoroughly described. The limitations of the study include challenges regarding executing scheduled interviews as research participants were busy or had their work schedules changed because of their work. The study was limited to employees of the Organisational Development because they were the ones who had good knowledge of TQM.

\section{RESEARCH FINDINGS}

The results presented and discussed on this section are based on three main interview questions which were posed to the participant during data collection phase.

\section{BENEFITS OF TQM}

The first category in the interviews wanted to find out the benefits of TQM. The results revealed that there were no visible benefits of TQM that had been experienced by the participants. Some of the statements which were taken from the participants indicating that they had not witnessed any TQM benefits in the GAUTENG included the following:

“There are no visible benefits from TQM that I have seen so far". Interview 1

"I have not seen any benefits because we don't have any in the city. We have no TQM at all". Interviewee 6

The study's findings also revealed that there were high levels of understanding of TQM at the Gauteng municipality. The participants clearly had knowledge of the fact that TQM was supposed to result in benefits to employees, customer services and they also talked about how TQM involved continuous improvement. Some of the statements which supported the notion that TQM was well understood under at the selected Gauteng municipality are as follows: 
An Investigation into Benefits and Challenges of Total Quality Management: The Case of a Gauteng Municipality

"My understanding of TQM is that it should benefit management, employees and customers or clients."

"TQM is not applied yet; at the moment we are not deriving any benefits from TQM"

The results also revealed that TQM in practice was not fully understood even its theoretical aspect was well understood. The participant complained that even though they understood what TQM was because of their levels of training received yet the concept was not fully explained. One of the participants that was interviewed (Interviewee 1) stated that TQM concept was not fully understood and also stated that as a result there were no benefits currently being reaped from the concept. Another interviewee, Interviewee 2 was quoted stating the following regarding TQM: "The understanding of $T Q M$ and the impact thereof is not recognized within the municipality because there is so much happening that we get clouded by processes and certain elements".

The primary research also revealed that the participants believed that there actually had been no TQM implementation in the Gauteng municipality. The participants in their responses in the interviews discussed the supposed benefits and they also exhibited high levels of understanding of TQM and they indicated that they had not witnessed any visible benefits of the quality programme. The most likely reason for participants to discuss everything else except the benefits was because TQM had not been implemented as far as Interviewee 3 is concerned. Interviewee 3 indicated that in his work he had not seen any evidence of TQM implementation. Interviewee 11 was quoted stating the following: "I don't believe that we are applying TQM in its truest sense we don't have any TQM programmes, we don't have a TQM function there is no oversight on a formalised way of TQM".

\subsection{Challenges in TQM Implementation}

The secondary category of the study was aimed at finding out the challenges facing the Gauteng municipality with regards to implementing TQM. The results are presented in this section.

The first challenge raised was related to top management support and commitment to TQM implementation. Top management was accused of not exhibiting any interest in issues relating to quality. Interviewee 1 stated that one of the biggest challenges facing TQM implementation was management's aloofness. According to Interviewee 4, the role of leadership was lacking, leadership needed to define where the organisation was supposed to go and clarify matters especially with regards to issues of the quality programme. In indicating that the Gauteng municipality had not shown commitment to the quality programme Interviewee 7 had the following to say: "Our leadership in the city is not coming to the party towards the achievement of city goals." The participant also complained about the lack leadership commitment. Interviewee 5 stated the following: "The city does not strive for continuous improvement, for it is a lip service, it's a lie in many cases."

The other challenge raised regarding management was that the top management lacked understanding. This lack of understanding of TQM by management is indicated in the two statements below:

Top management do not understand TQM they need to be educated on TQM.” Interviewee 12

"Some Top management understand TQM and some don't and those who do understand they fail to put proper strategies in place to achieve their goals". Interviewee 14

The other finding was that the Gauteng municipality lacked an effective communication strategy. The majority of the participants complained that management did not communicate well with the rest of the organisation's employees. Interviewee 2 stated that management did not communicate and consult employees. The lack of an effective communication strategy resulted in employees getting confused and not knowing what was actually expected of them.

The other challenge that was raised in the study was the presence of political interference as an obstacle in the implementation of TQM in the Gauteng municipality. A couple of statements which were taken from the participants which supported this notion are presented below:

"Duration of TQM implementation contributes to TQM being a challenge to implement taking into account the 5-year term of politics." Interviewee 9

"Political involvement in the city has an impact on the roll out of quality" Interviewee 11 
TQM implementation is more successful when an organisation's human resources are well trained. This brings us to the next challenge which is the lack of linkage between the Gauteng municipality's skills development strategy with the organisation's overall strategy. The participants highlighted that the Gauteng municipality was wasting financial resources on training and development as the skills obtained were not being utilised for the benefit of the organisation. The participants who shared this view forwarded the following statements:

"In most cases we go for training and on coming back we do not implement as a result there is no value for the Gauteng's investment from training. "Interviewee 1

"The city does not have a mechanism in place which measures the return on investment after an employee has attended training." Interviewee 13

The sixth challenge raised by the majority of the participant related to employee involvement. The participants indicated that there was a notable lack of employee involvement in the Gauteng municipality. The participants indicated that they did not know how their jobs fitted into the overall TQM programme. Some of the direct quotations from the participants indicated that there was lack of employee involvement include the following:

"Employees are not part of the strategy when it is developed, the strategy gets imposed that these are the targets and we need to achieve them". Interviewee 3

"You are called to a meeting without planning just to be told that this is how things are going to be done. There is no consultation at all." Interviewee 5

The other major challenge which stood in the way of a smooth implementation of TQM was the incompatibility between prevailing organisational culture and quality management philosophy. This was a sentiment shared by a number of interviewees who included Interviewees 5, 6, 8 and 9. Some of the statements which were taken from the participants indicating the issue of organisational culture incompatibility with TQM are as follows:

“Our organisational culture absolutely does not support TQM at all” Interviewee 5

"Broadly speaking I don't believe we have a culture that promotes quality but I do believe that there are pockets of excellence for example health" Interviewee 11

\section{Discussion OF RESUlts}

The key findings of the research included the fact the Gauteng municipality had not witnessed any benefits from TQM. The participants clearly indicated that they were not even sure that TQM had been implemented in the Gauteng municipality. This was an indication that successfully implementing TQM was not an easy task especially in the public sector. Previous studies support this finding, in that, Ready (2007:14) indicated that most of the challenges which confronted TQM implementation emanated from poorly designed bureaucratic systems. Bureaucracy by its very nature reduces flexibility and agility of an organisation and slows down work processes, and it ultimately impacts the effective delivery of public services (Imarhiagbe, 2015:74).

A lack of understanding of TQM and it impact would easily result in its benefits being obscured. Both employees and management need to be empowered through training and development initiatives in order for them to fully understand TQM. A study conducted in China by Kanji (2012:222) indicated that lack of knowledge was an obstacle to the implementation of TQM. The management of the Gauteng municipality was accused of lacking adequate knowledge required for the successful implementation of TQM. The lack of a leadership team which has the knowledge of TQM and the skills required to implement the quality management system coupled with a skills development strategy which is not aligned with the organisation's overall strategy hinders TQM implementation. Employees are obtaining training which the Gauteng municipality is not benefitting from because of organisation does not have a plan for how it will benefit from that training. The training obtained by employees and the lack of TQM knowledge and skills among management personnel presents a challenge for TQM implementation. 
A major organisation wide programme such as TQM requires top management support. The lack of adequate top management support negatively impacted TQM implementation at the Gauteng municipality. Mosadeghrad (2014:544) explicitly indicated that the success of TQM was heavily dependent on leadership and the commitment exhibited by senior management which is largely absent at Gauteng municipality. When organisational leaders are not visibly in support of TQM implementation programme, such an initiative eventually fails (Hill, 2008:39).

Political interference has been identified as one major obstacle in the implementation of TQM in the Gauteng municipality. A similar finding was made in a study conducted in Italy. According to Cassia and Magno (2011:8), the division among public administrators and political officials being councillors contributed to the reasons why municipalities in Italy were struggling to implement quality improvement practices. The same dilemma of the misalignment of interests between political leaders and administrators of municipalities such one of selected municipality in Gauteng contributes to failed TQM implementations in public sector settings. Unfortunately, politicians and administrators are all part of municipal and all government run entities and it is wise that the two camps find common understanding in order to overcome this obstacle.

A culture that is not consistent with a desire to attain outstanding quality was yet another obstacle to TQM implementation in the Gauteng municipality. The culture within this municipality was found to be inconsistent with the quality management system agenda. Khan (2006:6) suggested that a culture change was a prerequisite when dealing with matters of TQM implementation. The culture at the Gauteng municipality was supposed to change in order to bring a culture conducive to TQM implementation. The findings from the study confirmed the theory written by Khan (2006:6) regarding the need for a culture change.

\section{CONCLUSIONS AND RECOMMENDATIONS}

\subsection{Recommendations from Employees on TQM Implementation}

The findings from the secondary and primary studies of this study were in agreement. The purpose of the study was to investigate the extent to which the Gauteng municipality benefits from the implementation of Total Quality Management (TQM) and the challenges that prevents the municipality from achieving of full service TQM potential. Based on that purpose the secondary research revealed that one of the key benefits of TQM implementation was an increase in the quality of the organisation's services or products through process improvements (Kloppenborg, 2009: 286). The literature study also attempted to highlight the key challenges that impacted TQM implementation in Gauteng. It was discovered that lack of top management support, political divisions and issue of working in silos were among the key factors impacting implementation of the quality management system. The importance of leadership in improving quality was emphasised by Lee (2012:420).

The key primary findings in line with the purposes and aims of the study included the fact that the participant professed to have not witnessed any benefits of TQM in the Gauteng municipality. The implementation of TQM in the Gauteng municipality failed because of the lack of top management support. The management team of the Gauteng municipality also lacked the basic understanding of TQM and since the success of the quality management programme was dependent on senior management support, this was one of the factors that contributed towards the failure of its implementation. The political leadership in the Gauteng municipality was accused of interfering with the work of administrators and this further contributed to the failure of the implementation of the quality management system. The skills development strategy was not aligned to its overall strategy meaning that Gauteng municipality had not plan on how to utilise the skills obtained by its employees. An unsuitable organisational culture which was not conducive to TQM implementation was another factor found to be impacting the quality management philosophy in the Gauteng municipality.

\subsection{Recommendations}

- The organisation need to implement TQM philosophy and implement ISO9001 which addresses seven quality management principles which will simplify the implementation of a quality management system to address the Gauteng municipality's challenges for effectively implementing TQM. These principles are: customer focus; leadership; engagement of people; 
process approach; improvement; evidence-based decision making and relationship management.

- The second recommendation suggests that the Gauteng municipality needs to embark on a change management programme which will deal with the issues of culture change as well as making the organisation a quality oriented organisation which can easily accept and integrate TQM in their work processes. The change management is supposed to make use of internal organisational specialist as well as external consultants.

- In order address the issue of political interference, there is need for the formulation of a strategy document that can define the interactions of the political leadership with the administration. Such a document is supposed to ensure that political leadership does not meddle in the implementation of Gauteng strategy but is engaged as and when it is necessary. The political leadership will be expected to have an advisory role as the document will highlight and allow the administration to implement strategies that have been jointly discussed between political leadership and administrators.

- It will also be essential that the Gauteng municipality seeks to achieve alignment of its skills development strategy with its overall strategy. This can be achieved by having a high level document that defines the needs of the skills in the organisation. The training strategy should then be linked to the skills needs identified in the organisation.

\section{REFERENCES}

[1] Adams, K.A. \& Lawrence, E.K., 2015. Research Methods, Statistics, and Applicants. Los Angeles: SAGE.

[2] Ahmad, J., 2013. Local Government Bureaucracy and Implementation of Total Quality Management in Education Services Free In South Sulawesi Province. Public Policy and Administration Research, 3(8), pp.109-17.

[3] Al-Ibrahim, A., 2014. Quality Management and Its Role in Improving Service Quality in Public Sector. Journal of Business and Management Sciences, 2(6), pp.123-47.

[4] Altahayneh, Z.L., 2014. Implementation of Total Quality Management in Colleges of Physical Education in Jordan. International Journal of Business and Social Science, 5(3), pp.109-17.

[5] Ary, D., Jacobs, L.C., Sorensen, C.K. \& Walker, D., 2014. Introduction to Research in Education. 9th ed. Belmont: WADSWORTH CENGAGE Learning.

[6] Boulter, L., Bendell, T. \& Dahlgaard, J., 2013. Totaql quality beyond North America. International Journal of Operations and Production Management, 33(2), pp.197-215.

[7] Calvo-Mora, A., Picon, A., Ruiz, C. \& Cauzo, L., 2013. The relationships between soft-hard TQM factors and key business results. International Journal of Operations \& Production Management, 34(1), pp.11543.

[8] Cassia, F. \& Magno, F., 2011. Differences between public administrators and elected officials' perspectives on the role of the citizen in service quality improvement processes. The TQM Journal, 23(5), pp.550-59.

[9] Chaston, I., 2011. Public Sector Management: Mission Impossible? Hampshire: Palgrave Macmillan.

[10] Flick, U., ed., 2014. The SAGE Handbook of Qualitative Data Analysis. London: SAGE Publications, Ltd.

[11] Gharakhani, D., Rahmati, H., Farrokhi, M.R. \& Farahmandian, A., 2013. Total Quality Management and Organizational Performance. American Journal of Industrial Engineering, 1(3), pp.46-50.

[12] Grubor, A., Salai, S. \& Lekovic, B., 2009. Service Quality as a Factor of Marketing Competitiveness. Tirana: ASECU Association of Economic Universities of South and Eastern Europe and the Black Sea Region.

[13] Hill, D.A., 2008. What Makes Total Quality Management Work: A Study of Obstacles and Outcomes. Ann Arbor: ProQuest Information and Learning Company Capella University.

[14] Houser, J., 2015. Nursing Research: Reading, Using and Creating Evidence. Burlington: Jones \& Barlet Learning.

[15] Imarhiagbe, N., 2015. Managing Public Organization Through Leadership. Bloomington: Authorhouse.

[16] Jancicova, A. \& Brychta, K., 2009. TQM and Organisational Culture as Significant Factors in Ensuring Competitive Advantage: A Theoretical Perspective. Economics and Sociology, 2(1), pp.80-95.

[17] Juneja, D., Ahmad, S. \& Kumar, S., 2011. Adaptability of Total Quality Management to Service Sector. International Journal of Computer Science \& Management Studies, 11(2), pp.93-98. 
An Investigation into Benefits and Challenges of Total Quality Management: The Case of a Gauteng Municipality

[18] Kanji, G.K., 2012. Total Quality Management: Proceedings of the first world congress. London: Srpinger.

[19] Karami, A., 2016. Strategy Formulation in Entrepreneurial Firms. London: Routledge.

[20] Kazer, M.W. \& Grossman, S.C., eds., 2011. Gerontological Nurse Practitioner Certification Review. New York: Springer Publishing Company.

[21] Kessler, E.H., ed., 2013. Encyclopedia of Management Theory: Volume One. Los Angeles: Sage Publications.

[22] Khan, N., 2006. The Role of Culture in Successful Implementation of Quality Initiatives. In Pakistan's 10th International Convention on Quality Improvement. Lahore, 2006. PIQC.com.pk.

[23] Kloppenborg \& Timothy, J., 2009. Project Management: A Contemporary Approach. Cengage Learning.

[24] Mosadeghrad, A.M., 2014. Essentials of total quality management: a meta-analysis. International Journal of Health Care Quality Assurance, 27(6), pp.544-58.

[25] Neelankavil, J.P., 2011. International Business Research. New York: M.E. Sharp, Inc.

[26] Nieuwenhuizen, C., ed., 2011. Basics of Entrepreneurship. 2nd ed. Cape Town: Juta and Company Ltd.

[27] Nikolic, V. \& Nastasic, A., 2010. Organizational Culture as Significant Factor. International Journal for Quality research, 4(1), pp.59-69.

[28] Pride, W., Hughes, R. \& Kapoor, J., 2010. Business. Mason: Cengage Learnig.

[29] Ready, D.H., 2007. The Critical Role of City and County Managers in Quality Management Implementation. PhD Thesis. ProQuest Information and Learning Company.

[30] Suleman, Q. \& Gul, R., 2015. Challenges to Successful Total Quality Management Implementation in Public Secondary Schools: A Case Study of Kohat District, Pakistan. Journal of Education and Practice, 6(15), pp.123-34.

[31] Teddlie, C. \& Tashakkori, A., eds., 2009. Foundations of Mixed Methods Research: Integrating Quantitative and Qualitative Approaches in the Social and Behavioral Sciences. Thousand Oaks: Sage Publications.

[32] Werner, A. et al., 2011. Organisational Behavior: A contemporary South African perspective. Pretoria: Van Schaic.

[33] Werner, J.M. \& DeSimone, R.L., 2012. Human Resource Development. 6th ed. Mason: Cengage Learning.

Citation: Boitumelo Leenetse Mabele, Shamila Singh. "An Investigation into Benefits and Challenges of Total Quality Management: The Case of a Gauteng Municipality" International Journal of Managerial Studies and Research (IJMSR), vol 6, no. 2, 2018, pp. 44-54. doi:http://dx.doi.org/10.20431/2349-0349.0602005.

Copyright: () 2018 Authors. This is an open-access article distributed under the terms of the Creative Commons Attribution License, which permits unrestricted use, distribution, and reproduction in any medium, provided the original author and source are credited. 